\title{
Recria de Novilhos Mestiços em Pastagens de Brachiaria brizantha, com Diferentes Níveis de Suplementação, na Região Amazônica. Desempenho Animal ${ }^{1}$
}

\section{Rafael Henrique de Tonissi e Buschinelli de Goes², Antonio Bento Mancio ${ }^{3}$, Rogério de Paula Lana $^{3}$, Dorismar David Alves ${ }^{4}$, Maria Ignez Leão ${ }^{3}$, Alonso Thiago Silvestre Silva ${ }^{5}$}

RESUMO - O objetivo neste trabalho foi avaliar o efeito de diferentes níveis de suplementação sobre o desempenho de novilhos recriados a pasto. Cinqüenta e cinco novilhos com média de 10 meses de idade e peso inicial de $226 \mathrm{~kg}$ foram distribuídos em delineamento inteiramente casualizado. Os tratamentos consistiram no fornecimento de suplemento nas quantidades de 0,125; 0,25; 0,50 e $1,0 \%$ do peso vivo e do tratamento controle (sal mineral). Os suplementos foram à base de milho e farelo de soja, com teor de $24 \%$ de proteína bruta. Os animais do grupo controle apresentaram consumo médio de 70 g/dia, com ganho de 0,28 kg. A resposta dos animais ao suplemento mineral foi limitada pela proteína, não permitindo o atendimento das exigências de ganho. Os demais tratamentos apresentaram ganhos de 0,$51 ; 0,58 ; 0,68$ e 0,72 kg/dia, com conversão de 1,48, 1,56, 2,67 e 4,43 kg de suplemento por kg de ganho, durante o período de transição, e 1,52; 3,17; 5,29 e 10,19, durante o período da seca, para 0,125; 0,25; 0,5 e 1,0\%PV. A suplementação em níveis crescentes proporcionou maiores ganhos de peso nos níveis de 0,5 e 1,0\%, com maior eficiência de uso do suplemento para os níveis de 0,125 e 0,25\%.

Palavras-chave: eficiência do suplemento, farelo de soja, ganho de peso, milho, suplementação protéica

\section{Effects of Different Supplementation Levels on Animal Performance of Post Weaning Steers Grazing Brachiaria brizantha, in the Amazonian Area}

\begin{abstract}
The objective of this trial was to evaluate the effects of different levels of supplementation on performance of grazing steers in the growing phase. The experiment was carried from March to November 2003. Fifty-five steers averaging 10 months old and initial body weight of $226 \mathrm{~kg}$ were assigned to a completely randomized design. The treatments were as follows: control (mineral salt) and supplements fed at different levels $(0.125,0.25,0.50$, and $1.0 \%$ body weight/animal/day) and contained corn and soybean meal formulated to yield $24 \%$ crude protein. The control group intaked $70 \mathrm{~g} /$ day and averaged daily gain of $0.28 \mathrm{~kg}$. The control group showed protein content below the threshold value, which did not meet gain requirements. Animals fed other treatments averaged daily gain of $0.51,0.58,0.68$ and $0.72 \mathrm{~kg} /$ day, with the supplement conversion of 1.48, 1.56, 2.67 and 4.43, during the transition time, and 1.52, 3.17, 5.29 and 10.19 , during the dry season, for $0.12 ; 0.25 ; 0.5$ and $1.0 \%$ BW. The supplementation provided higher values of weight gain at the levels of $0.5 \%$ and $1.0 \%$, with higher efficiency at the levels of 0.125 and $0.25 \%$.
\end{abstract}

Key Words: corn, daily gain, efficiency of the supplement, protein supplementation, soybean meal

\section{Introdução}

O Brasil possui um rebanho bovino de aproximadamente 185 milhões de cabeças contribuindo com apenas 54\% da produção sul-americana e $11 \%$ da produção mundial. O abate de aproximadamente 37 milhões de bovinos por ano produz um montante de 6,67 milhões de toneladas de equivalente de carcaça (FNP, 2003), colocando o país, em 2003, como o maior exportador mundial de carne bovina.

Este panorama desafia a pecuária nacional à produção de carne de forma eficiente, com qualidade e a baixo custo, proveniente de animais com idade de abate próxima a 24 meses. Para atingir esta idade, os animais, quando jovens, devem apresentar ganhos de, no mínimo, 0,60 kg/dia (Paulino, 1999). A fase de recria, responsável por 58\% do ciclo de produção, seria a principal etapa para melhor eficiência no processo produtivo.

As pastagens tropicais apresentam períodos distintos de produção forrageira. Portanto, práticas de manejo adequadas, como a suplementação das pastagens (protéica ou energética) apresentam excelentes resultados para o desempenho animal, quando compa-

\footnotetext{
${ }_{1}^{1}$ Parte do projeto financiado pelo CNPq.

2 Zootecnista, DS, Professor da Universidade Estadual de Maringá -UEM/Campus de Umuarama/PR-CCA. Av: Colombo, 5790 - CEP: $87020-$ 900. Maringá/PR (rgoes@elitnet.com.br).

3 Professores do Departamento de Zootecnia - UFV. Viçosa/MG. 36571-000 (amancio@ufv.br; rlana@ufv.br).

${ }^{4}$ Zootecnista. MS. Estudante de Doutorado, DZO/UFV. Viçosa/MG. 36571-000.

5 Eng. Agrônomo/UEMS (Ialonsoss@terra.com.br).
} 
radas com suplementação mineral, compensando perdas ocorridas durante períodos de baixa produção.

A produção de $\mathrm{N}$ microbiano no rúmen pode ser limitada em algumas gramíneas tropicais, em razão do suprimento de substratos prontamente fermentáveis. Desta forma, a suplementação de grãos em pequenas quantidades pode elevar o $\mathrm{N}$-microbiano que alcança o intestino, melhorando, conseqüentemente, o desempenho animal (Caton \& Dhuyvetter, 1997).

A suplementação de animais em pastejo pode ser feita em até $0,5 \%$ do peso vivo (PV), sem decrescer o consumo de forragem (Horn \& McCollun, 1987). O suplemento de $0,3 \% \mathrm{PV}$ quando totalmente adicionado à pastagem, entre 0,3 e 1,0\%PV proporciona, para cada $500 \mathrm{~g}$ fornecidos, redução no consumo da pastagem de aproximadamente 300 g (Herd em 1997, citado por Thiago, 2000).

Kunkle et al. (2000) afirmaram que pode-se aumentar a resposta dos animais com a suplementação energética em baixos níveis por longos períodos, em forragens de boa qualidade, em vez de se fornecer altos níveis, com disponibilidades elevadas de forragens.

O efeito na redução do consumo e da digestibilidade é mais pronunciado com a suplementação em altos níveis, com a presença de carboidratos não-estruturais - CNE (amido e açúcares) em função da queda do pH ruminal e da redução do crescimento bacteriano (Dixon \& Stockdale, 1999). A suplementação com produtos fibrosos, com alto NDT (>75\%) e baixa proporção de CNE (<30\%), resulta em menor impacto sobre o consumo e a digestibilidade (Kunkle et al., 2000).

Efeitos positivos sobre o ganho de peso ocorrem quando o consumo de proteína é maior $0,1 \%$ PV, com pequena diferença entre as fontes de proteína. Pequenos efeitos no ganho de peso são encontrados quando o consumo de proteína é baixo, sendo estes confundidos com o tipo de pastagem e o suplemento fornecido (Moore et al., 1999).

Estudando níveis de NDT similares para milho e soja em grão, Garces-Yepez et al. (1997) encontraram ganhos similares com a suplementação de aproximadamente 0,5\% PV. Entretanto, com níveis de 1,0\% PV, os ganhos apresentaram aumento de 10 a $25 \%$. Os efeitos da suplementação com milho e grão de soja sobre o consumo e a digestibilidade da forragem mostraram-se vantajosos, especialmente quando os animais foram alimentados com níveis acima de 0,5\% PV (Kunkle et al., 2000).
Santos et al. (2004) destacaram que a suplementação de bovinos em pastejo deve ser feita na proporção de 0,8 a 1,0\% de peso vivo. Euclides et al. (2001), suplementando animais mantidos em pastagens animais com concentrado protéico e energético a $0,8 \%$ do peso vivo, durante a seca, encontraram melhor desempenho dos animais quando comparado à suplementação mineral.

No entanto, este melhor desempenho não foi suficiente para compensar os custos adicionais da suplementação. A utilização de suplementação com 0,1 a $0,2 \%$ PV pode ser uma alternativa de baixo custo, em função do baixo consumo proporcionado por estes suplementos. Goes et al. (2003b), suplementando novilhos com 0,15\% PV, encontraram melhor desempenho destes animais, quando comparado aos que receberam apenas sal mineral. Zervoudakis et al. (2001) e Prado et al. (2002), no entanto, demonstraram que a suplementação protéica com 0,6 e $0,3 \%$ de peso vivo no período das águas, não trouxe benefícios aos animais quando comparada à suplementação mineral.

O objetivo neste trabalho foi avaliar o efeito e a eficiência dos diferentes níveis de suplementação sobre o desempenho de novilhos mestiços recriados em pastagens de Brachiaria brizantha, cv Marandu na região amazônica.

\section{Material e Métodos}

O experimento foi desenvolvido nos meses de março a novembro de 2003, na Fazenda Rancho SS localizada no município de Alta Floresta-MT (953'02“de latitude sul, 56²14'38” de longitude oeste e $288 \mathrm{~m}$ do nível do mar). O clima predominante na região é o equatorial úmido e quente, com nítida estação seca e temperatura anual média de $26^{\circ} \mathrm{C}$ e precipitação de $2.750 \mathrm{~mm}$ por ano. O período experimental foi dividido em dois períodos distintos, denominados períodos de transição águas-seca e período de seca. O período de transição durou 84 dias (10 de abril a 2 de julho) e a seca, 113 dias (3 de julho a 01 de novembro). A precipitação total e as temperaturas mínima e máxima encontram-se na Tabela 1.

O experimento foi implantado em uma área com pastagem de Brachiaria brizantha, cv. Marandu, estabelecida entre os anos de 1991 e 1992, sem adubação ou outra prática de manejo, pastejada desde sua implantação. A área experimental de 24,5 ha foi dividida em cinco piquetes, providos de cochos cobertos com duplo acesso e "aguadas". 
Tabela 1 - Temperaturas médias mensais mínimas e máximas, precipitação e umidade relativa do ar, entre os períodos experimentais

Table 1 - Averages of monthly minimum and maximum temperatures, precipitation and relative air moisture, during the experimental periods

\begin{tabular}{|c|c|c|c|c|c|}
\hline \multirow[t]{3}{*}{$\begin{array}{l}\text { Mês } \\
\text { Month }\end{array}$} & \multicolumn{3}{|c|}{$\begin{array}{c}\text { Temperatura do ar }\left({ }^{\circ} \mathrm{C}\right) \\
\text { Airtemperature }\end{array}$} & \multirow[t]{3}{*}{$\begin{array}{l}\text { Precipitação } \\
\text { Precipitation }\end{array}$} & \multirow[t]{3}{*}{$\begin{array}{c}\text { Umidade relativa (\%) } \\
\text { Relative moisture }\end{array}$} \\
\hline & \multicolumn{3}{|c|}{$\begin{array}{l}\text { Média mensal } \\
\text { Monthly average }\end{array}$} & & \\
\hline & $\begin{array}{l}\text { Média } \\
\text { Medium }\end{array}$ & $\begin{array}{l}\text { Mínima } \\
\text { Minimum }\end{array}$ & $\begin{array}{l}\text { Máxima }(\mathrm{mm}) \\
\text { Maximum }\end{array}$ & & \\
\hline Março (March) & 25,3 & 20,7 & 33,2 & 439 & 85 \\
\hline Abril(April) & 24,3 & 19,8 & 33,4 & 76 & 86 \\
\hline Maio (May) & 22,1 & 19,1 & 29,7 & 137 & 86 \\
\hline Junho (June) & 24,9 & 14,1 & 34,4 & 26 & 83 \\
\hline Julho (July) & 24,3 & 17,2 & 33,8 & 00 & 63 \\
\hline Agosto (August) & 26,2 & 19,4 & 35,5 & 00 & 80 \\
\hline Setembro (September) & 25,8 & 21,0 & 36,3 & 158 & 87 \\
\hline
\end{tabular}

Foram utilizados 55 novilhos com média 10 meses de idade e peso inicial de $226 \pm 24 \mathrm{~kg}$ (26F1 Santa Gertrudis x Nelore, 14 F1 Simental x Nelore e 15 Nelore). Os animais foram identificados, pesados e distribuídos, de forma homogênea e aleatória nos piquetes, a fim de se garantir as médias de peso vivo e os grupos genéticos semelhantes entre os tratamentos. As pesagens foram feitas a cada 21 dias.

Os animais foram mantidos em pastagem de $B$. brizantha e receberam apenas suplementação mineral antes do experimento. Todos os animais foram vacinados contra febre aftosa e desverminados com vermífugo a base de Moxidectina a $1 \%$ (Cydectin ${ }^{\circledR}$ NF). A vermifugação foi repetida a cada 60 dias e o controle da mosca-do-chifre foi realizado com o uso de inseticidas à base de cipermetrina e organofosforados, a cada 21 dias, de acordo com as necessidades.

Os tratamentos consistiram da suplementação controlada de acordo com o peso vivo dos animais, nas quantidades de 0,$125 ; 0,25 ; 0,5$ e $1,0 \% \mathrm{PV}$, mais o grupo controle, que recebia apenas suplementação mineral à vontade. Todos os suplementos foram à base de milho e farelo de soja, com teor de $24 \%$ de proteína bruta (Tabelas 2, 3, e 4).

Os suplementos foram fornecidos diariamente, por volta das $8 \mathrm{~h}$, para não interferirem no comportamento de pastejo dos animais. O consumo de suplemento foi controlado pelo fornecimento restrito, de acordo com o peso dos animais, sendo corrigido a cada 21 dias, após a pesagem.
Tabela 2 - Composição (\%) dos suplementos utilizados e custo $(R \$)$ por quilo de produto

Table 2 - Content (\%) of supplements and cost (R\$) by $\mathrm{kg}$ of product

\begin{tabular}{|c|c|c|c|c|}
\hline \multirow[b]{2}{*}{$\begin{array}{l}\text { Ingrediente } \\
\text { Ingredient }\end{array}$} & \multicolumn{4}{|c|}{$\begin{array}{c}\text { Fornecimento do suplemento (\%PV) } \\
\text { Supplement level }(\% B W)\end{array}$} \\
\hline & 0,125 & 0,25 & 0,50 & 1,0 \\
\hline $\begin{array}{l}\text { Milho grão } \\
\text { Corn grain }\end{array}$ & 53,47 & 68,64 & 77,75 & 81,20 \\
\hline $\begin{array}{l}\text { Farelo de soja } \\
\text { Soybean meal }\end{array}$ & 10,00 & 10,00 & 10,00 & 10,00 \\
\hline $\begin{array}{l}\text { Amiréia } 180 \\
\text { Amirea } 180\end{array}$ & 6,10 & 6,60 & 6,92 & 6,94 \\
\hline Sal (NaCl)(Salt) & 15,00 & 7,50 & 3,00 & 1,00 \\
\hline $\begin{array}{l}\text { Fosfato bicálcico } \\
\text { Dicalcium phosphate }\end{array}$ & 5,79 & 2,48 & 0,49 & - \\
\hline $\begin{array}{l}\text { Premix mineral } \\
\text { Mineral mixture }\end{array}$ & 2,00 & 1,00 & 0,40 & 0,20 \\
\hline $\begin{array}{l}\text { Calcário calcítico } \\
\text { Limestone }\end{array}$ & 7,68 & 3,78 & 1,44 & 0,66 \\
\hline $\begin{array}{l}\text { Custo }(\mathrm{R} \$) \\
\text { Cost }(R \$)\end{array}$ & 0,42 & 0,42 & 0,42 & 0,42 \\
\hline
\end{tabular}

A coleta de amostras para estimar a disponibilidade da forrageira foi realizada no $1^{\circ}$ dia experimental, pelo corte de 10 áreas por piquete, escolhidas aleatoriamente e delimitadas por um quadrado metálico, de $0,25 \mathrm{~m}^{2}$ de área. As amostras foram separadas em duas porções, para avaliação da disponibilidade de matéria seca (MS) e das frações folha, colmo e material morto. 
Tabela 3 - Composição percentual do suplemento mineral e custo $(R \$)$ por quilo de produto

Table 3 - Composition (\%) of the mineral supplement and cost $(R \$)$ by $\mathrm{kg}$ of product

\begin{tabular}{lc}
\hline $\begin{array}{l}\text { Ingrediente } \\
\text { Ingredient }\end{array}$ & $\begin{array}{c}\text { Mistura mineral (\%) } \\
\text { Mineral mixture (\%) }\end{array}$ \\
\hline $\begin{array}{l}\text { Fosfato bicálcico } \\
\text { Dicalcium phosphate } \\
\text { Calcário } \\
\text { Limestone }\end{array}$ & 44,44 \\
Sal & 14,82 \\
Salt & 37,72 \\
Sulfato de cobre & \\
Copper sulfate & 0,57 \\
Sulfato de manganês & \\
$\begin{array}{l}\text { Manganese sulfate } \\
\text { Óxido de zinco } \\
\text { Zinc oxide } \\
\text { Sulfato de cobalto } \\
\text { Cobalt sulfate }\end{array}$ & 0,40 \\
Iodato de cálcio \\
Calcium iodine \\
$\begin{array}{l}\text { Enxofre ventilado } \\
\text { Sulphur } \\
\text { Selenito de sódio } \\
\text { Sodium selenite } \\
\text { Custo (R } \$ \text { ) } \\
\text { Cost - R\$ }\end{array}$ \\
\hline
\end{tabular}

Tabela 4 - Composição bromatológica dos suplementos utilizados

Table 4 - Chemical composition of the supplements

\begin{tabular}{|c|c|c|c|c|c|}
\hline & \multicolumn{5}{|c|}{$\begin{array}{c}\text { Fornecimento do suplemento }(\% \mathrm{PV}) \\
\text { Supplement level }(\% B W)\end{array}$} \\
\hline & $\begin{array}{l}\mathrm{SM} \\
\mathrm{MM}\end{array}$ & 0,125 & 0,25 & 0,50 & 1,00 \\
\hline $\mathrm{PB}(C P)(\%)$ & - & 24,0 & 24,0 & 24,0 & 24,0 \\
\hline FDN (NDF) (\%) & - & 14,50 & 16,6 & 25,5 & 27,1 \\
\hline $\mathrm{EE}(\%)$ & - & 2,47 & 1,93 & 3,06 & 3,26 \\
\hline Cinzas (Ash) (\%) & 85,86 & 24,73 & 12,27 & 5,50 & 3,20 \\
\hline $\operatorname{NDT}(T D N)(\%)$ & )$^{1}-$ & 52,7 & 65,02 & 72,42 & 75,19 \\
\hline $\mathrm{Ca}(\%)$ & 18,72 & 3,0 & 1,5 & 0,60 & 0,50 \\
\hline $\mathrm{P}(\%)$ & 8,72 & 2,0 & 1,0 & 0,40 & 0,23 \\
\hline $\mathrm{Na}(\%)$ & 13,98 & 5,56 & 2,78 & 1,12 & 0,38 \\
\hline $\operatorname{Mg}(\%)$ & 1,14 & 0,57 & 0,34 & 0,2 & 0,16 \\
\hline $\mathrm{S}(\%)$ & 1,50 & 0,61 & 0,38 & 0,24 & 0,19 \\
\hline $\mathrm{Cu}(\mathrm{ppm})$ & 1450,0 & 335,42 & 170,93 & 72,24 & 39,35 \\
\hline $\operatorname{Mn}(\mathrm{ppm})$ & 1250,0 & 84,99 & 45,61 & 21,98 & 14,13 \\
\hline $\mathrm{Zn}(\mathrm{ppm})$ & 5000,0 & 1008,05 & 509,56 & 210,48 & 110,82 \\
\hline $\mathrm{Co}(\mathrm{ppm})$ & 100,0 & 28,03 & 14,04 & 5,64 & 2,84 \\
\hline $\mathrm{I}(\mathrm{ppm})$ & 80,0 & 15,06 & 7,56 & 3,09 & 1,59 \\
\hline Se (ppm) & 28,0 & 2,04 & 1,04 & 0,44 & 0,25 \\
\hline $\mathrm{F}(\mathrm{ppm})$ & 800,0 & 241,09 & 103,22 & 20,51 & - \\
\hline
\end{tabular}

$\mathrm{SM}=$ suplementação mineral. ${ }^{1} \mathrm{NDT}=\mathrm{PBD}+2,25 \mathrm{EED}+\mathrm{FDNcpD}$ + CNFD.

$M M=$ mineral mixture. $1 T D N=D C P+2.25 D E E+D N D F a p+D N F C$
Para avaliação da dieta volumosa ingerida, foi utilizado o método do pastejo simulado, conforme descrito por Johnson (1978), pela observação cuidadosa da preferência animal quanto às partes ingeridas da planta, da área pastejada, da altura e das partes consumidas. As amostras foram colhidas pelo mesmo observador, manualmente, para evitar discrepâncias entre as coletas.

Todas as amostras foram armazenadas em sacolas plásticas, previamente identificadas, congeladas à $-10^{\circ} \mathrm{C}$ e transportadas para o Laboratório de Nutrição Animal da Universidade Federal de Viçosa, para análises posteriores.

Após descongelamento à temperatura ambiente e secagem em estufa ventilada a $65^{\circ} \mathrm{C}$, por 72 horas, as amostras foram processadas em moinhos do tipo Willey, com peneira de malha de $1 \mathrm{~mm}$, determinando-se os teores de proteína bruta (PB), extrato etéreo (EE), fibra em detergente neutro (FDN) e fibra em detergente ácido (FDA), lignina (LIG), cinzas (CZ) e minerais, conforme descrito por Silva \& Queiroz (2002). A digestibilidade in vitro da matéria seca (DIVMS) foi determinada pela técnica de Tilley \& Terry (1963) modificada.

O delineamento estatístico foi inteiramente casualizado (DIC), com cinco tratamentos e 11 repetições. Os dados foram interpretados por meio das análises de variância e de regressão, obtidas pelo programa estatístico SAEG (UFV, 2000). As médias de ganho de peso foram comparadas pelo teste Tukey, a 5\% de probabilidade, segundo o modelo: $\hat{\mathrm{Y}}_{\mathrm{ij}}$

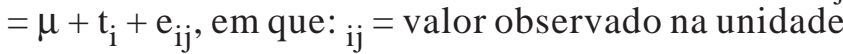
experimental que recebeu o nível de suplementação i na repetição $\mathrm{j} ; \mu=$ média geral; $\mathrm{t}_{\mathrm{i}}=$ efeito do nível de suplementação $i$, sendo $i=1$, 2, 3, 4; 5 e e $e_{i j}=$ erro aleatório, associado a cada observação tratamento i e repetição j.

\section{Resultados e Discussão}

Todos os animais foram submetidos a altas disponibilidades de forragem para garantir a seletividade, que, de acordo com Minson (1990) e Euclides et al. (1998), deve ser de 2.000 e $2.500 \mathrm{~kg}$ de MS/ha, respectivamente. Os dados referentes à disponibilidade, porcentagens de caule, de folhas e material morto e de altura da pastagem, em função dos tratamentos, encontram-se na Tabela 5. 
O pastejo simulado é uma alternativa para substituição do método da extrusa (De Vries, 1995, Euclides et al., 1992; Goes et al., 2003a). Porém, a simulação seria eficiente quando possui elevada quantidade de forragem disponível (Morais et al., 1998).

Os dados referentes ao ganho médio de peso durante os períodos estão presentes na Tabela 6. Os animais que receberam somente suplementação mineral consumiram em média $70 \mathrm{~g} / \mathrm{animal} /$ dia e alcançaram baixo ganho de peso $(0,26 \mathrm{~kg} / \mathrm{animal}$ e $0,29 \mathrm{~kg} / \mathrm{animal}$, respectivamente, para os períodos de transição e seca).

A relação NDT:PB da forragem foi superior a 7,0 (Tabela 5), o que indica um déficit de proteína em relação à energia (Moore et al., 1999). Com isso, o fornecimento de suplementação protéica pode levar a melhora o desempenho animal. Esta relação justifica o maior desempenho de animais suplementados com diferentes níveis de fornecimento e o baixo ganho de peso daqueles que receberam somente suplementação mineral.

A resposta dos animais ao suplemento mineral pode tornar-se limitada, uma vez que a proteína é o nutriente limitante, não permitindo o atendimento das exigências nutricionais (Lana, 2000, 2002). Segundo Lana (2000), o potencial de ganho em pastagem com $8,3 \% \mathrm{~PB}$ e $65,57 \%$ DIVMS seria de $0,72 \mathrm{~kg} / \mathrm{dia}$, superior ao apresentado neste trabalho.

Os animais que receberam suplementação de $0,5 \%$ e $1,0 \%$ PV apresentaram peso vivo final semelhante, ao final dos períodos estudados. Durante o período de transição, ocorreram diferenças entre os níveis de suplementação, com maiores ganhos de peso para os animais alimentados com 0,5 e 1,0\%PV. Estes dados estão de acordo com os limites apresentados por Paulino (2000) e Santos et al. (2004), de 0,8 a 1,0\% de peso vivo, como favoráveis ao desempenho animal.

Kabeya et al. (2002), suplementando animais a 0,9\%PV com um suplemento contendo $30 \%$ PB, não encontraram diferenças entre o milho desintegrado de palha e sabugo (MDPS), milho e farelo de trigo, que apresentaram ganhos de 0,85, 0,88 e 0,80 kg/dia entre os meses de transição águas-seca, semelhantes ao ganho apresentado por este trabalho, de $0,84 \mathrm{~kg} / \mathrm{dia}$, com um suplemento à base de milho e farelo de soja, com 24\% de PB. Manella et al. (2002) obtiveram ganhos de peso de $0,78 \mathrm{~kg} / \mathrm{dia}$, em pastagens de $B$. brizantha durante o período das águas, semelhantes aos obtidos para o nível de 0,5\% de PV.

A suplementação protéica para novilhos durante a fase de transição, em pastagens de $B$. brizantha com
0,6\% PV de farelo de algodão, proporcionou ganhos de $1,14 \mathrm{~kg} /$ dia. A associação de energia (suplemento protéico-energético) alterou o nível de fornecimento para $1,0 \% \mathrm{PV}$, e o ganho em 1,07 kg/dia, superiores ao apresentado neste experimento. Peruchena (1999) observou que a suplementação permitiu terminar os animais entre 20 e 22 meses de idade, de modo que a dieta protéica de $0,6 \% \mathrm{PV}$ teve menor custo se comparada com a suplementação protéico-energética a 1,0\%PV. Os resultados apresentados na Tabela 6 indicam tendências semelhantes à encontrada por este autor, porém, com ganho menores.

Tabela 5 - Disponibilidade média (t MS/ha), altura $(\mathrm{cm})$, porcentagens de folhas, de caule e de material morto da pastagem de $B$. brizantha e composição química da forragem selecionada pelos bovinos, em função dos diferentes tratamentos

Table 5 - Mean availability (t DM/ha), height (cm), percentages of leaves, steams and dead material of $B$. brizantha pasture and chemical composition of the forage selected by the bovines, according to treatments

\begin{tabular}{|c|c|c|c|c|c|}
\hline & \multicolumn{5}{|c|}{$\begin{array}{c}\text { Fornecimento do suplemento (\% PV) } \\
\text { Supplement level }(\% B W)\end{array}$} \\
\hline & $S M(M M)$ & 0,125 & 0,25 & 0,50 & 1,00 \\
\hline $\begin{array}{l}\text { Disponibilidade } \\
\text { (t MS/ha) } \\
\text { Availability } \\
\text { (t DM/ha) }\end{array}$ & 6,93 & 8,33 & 9,45 & 9,99 & 8,93 \\
\hline $\begin{array}{l}\text { Altura }(\mathrm{cm}) \\
\text { Height }(\mathrm{cm})\end{array}$ & 70,00 & 67,00 & 72,50 & 71,00 & 71,00 \\
\hline $\begin{array}{l}\text { Folhas (\%) } \\
\text { Leaves (\%) }\end{array}$ & 19,50 & 20,00 & 20,00 & 19,00 & 18,00 \\
\hline $\begin{array}{l}\text { Caule (\%) } \\
\text { Steams (\%) }\end{array}$ & 68,00 & 66,50 & 64,50 & 68,00 & 69,00 \\
\hline $\begin{array}{l}\text { Material morto (\%) } \\
\text { Dead material (\%) }\end{array}$ & 12,50 & 13,50 & 15,50 & 13,00 & 13,00 \\
\hline $\mathrm{PB}(C P)(\%)$ & 8,33 & 6,25 & 6,79 & 7,18 & 7,32 \\
\hline FDN (NDF) (\%) & 67,93 & 71,66 & 70,08 & 71,65 & 69,98 \\
\hline FDA $(A D F)(\%)$ & 36,18 & 40,91 & 38,44 & 43,63 & 37,96 \\
\hline LIG(\%) & 6,89 & 10,70 & 8,89 & 9,82 & 7,38 \\
\hline $\begin{array}{l}\text { DIVMS (\%) } \\
\text { IVDMD }\end{array}$ & 65,69 & 53,08 & 60,93 & 62,28 & 60,98 \\
\hline $\begin{array}{l}\text { Cinzas (\%) } \\
\text { Ash }\end{array}$ & 8,21 & 8,55 & 8,4 & 8,07 & 7,86 \\
\hline $\mathrm{Ca}(\%)$ & 0,30 & 0,26 & 0,26 & 0,24 & 0,30 \\
\hline $\mathrm{P}(\%)$ & 0,19 & 0,17 & 0,16 & 0,18 & 0,20 \\
\hline $\begin{array}{l}\mathrm{CHOT}(\%)^{1} \\
\text { TC }\end{array}$ & 81,47 & 83,19 & 82,39 & 82,75 & 82,99 \\
\hline $\begin{array}{l}\text { NDT/PB } \\
T D N / C P\end{array}$ & 7,89 & 8,49 & 8,97 & 8,67 & 8,33 \\
\hline
\end{tabular}

$\mathrm{SM}=$ Sal mineral. ${ }^{1} \mathrm{CHOT}=$ carboidratos totais $[100-$ (\%PB+\%EE+\%CZ)].

$M M=$ mineral mixture. ${ }^{1} T C=$ total carbohydrates $[100-(\% C P+\% E E+\% A s h)]$. 
Tabela 6 - Ganho de peso médio durante os períodos de transição e de seca dos animais suplementados em diferentes níveis, em função do peso vivo

Table 6 - Mean weight gain during the dry to rainy transition season and dry season of animals supplemented at different levels, according to body weight

\begin{tabular}{|c|c|c|c|c|c|c|}
\hline & \multicolumn{5}{|c|}{$\begin{array}{l}\text { Fornecimento do suplemento (\% PV) } \\
\text { Supplement level }(\% B W)\end{array}$} & \multirow[t]{2}{*}{ CV (\%) } \\
\hline & $\begin{array}{l}\mathrm{SM} \\
M M\end{array}$ & 0,125 & 0,25 & 0,50 & 1,00 & \\
\hline $\begin{array}{l}\text { Peso vivo inicial } \\
\text { no período de transição }(\mathrm{kg}) \\
\text { Initial weight in } \\
\text { the transition period }(\mathrm{kg})\end{array}$ & 226,9 & 232,0 & 219,1 & 231,3 & 221,6 & 10,6 \\
\hline $\begin{array}{l}\text { Peso vivo final no período de } \\
\text { transição e início do período de } \\
\text { seca }(\mathrm{kg}) \\
\text { Final weight in the } \\
\text { transition and initial } \\
\text { in the dry period }(\mathrm{kg})\end{array}$ & $248,7 b$ & $271,4 a b$ & 273,7ab & 294,3a & 291,9ab & 12,2 \\
\hline $\begin{array}{l}\text { Peso vivo final no } \\
\text { período de seca }(\mathrm{kg}) \\
\text { Final weight in the dry period }(\mathrm{kg}) \\
\text { Ganho médio diário }(\mathrm{kg} / \mathrm{dia}) \\
\text { Average daily gain }(\mathrm{kg} / \text { day })\end{array}$ & 281,5b & 332,5ab & 333,6ab & $362,1 \mathrm{a}$ & $360,1 a$ & 13,2 \\
\hline $\begin{array}{l}\text { Período de transição } \\
\text { Dry to rainy transition season }\end{array}$ & $0,26 \mathrm{~d}$ & $0,47 \mathrm{c}$ & $0,65 b$ & $0,75 \mathrm{ab}$ & $0,84 a$ & 24,9 \\
\hline $\begin{array}{l}\text { Período de seca } \\
\text { Dry season }\end{array}$ & $0,29 b$ & $0,54 a$ & 0,53a & 0,60a & $0,61 \mathrm{a}$ & 26,9 \\
\hline $\begin{array}{l}\text { Média ponderada } \\
\text { Weighed mean }\end{array}$ & $0,28 d$ & $0,51 \mathrm{c}$ & $0,58 \mathrm{bc}$ & 0,68ab & $0,72 \mathrm{a}$ & 16,9 \\
\hline
\end{tabular}

Médias na linha seguidas de letras diferentes diferem $(P<0,05)$ entre si pelo teste Tukey.

Means in the row followed by different letters are different $(P<0.05)$ by Tukey test.

Zervoudakis (2003) verificou ganho de $0,54 \mathrm{~kg} / \mathrm{dia}$, com suplementação protéico-energética a $0,2 \%$ do PV, em função da presença de fontes naturais de proteína (farelo de soja), semelhante aos ganhos obtidos para o nível de 0,25\%PV na transição de $0,65 \mathrm{~kg} /$ dia. Em suplementos de baixo consumo, a adição do farelo de soja seria benéfica para o fornecimento de ácidos graxos de cadeia ramificada aos microrganismos ruminais (Paulino et al., 2001).

Entre os níveis de suplementação, o fornecimento de $0,125 \% \mathrm{PV}$ proporcionou o menor ganho de peso, de $0,47 \mathrm{~kg} /$ dia, inferior ao encontrado por Goes et al. (2003b), de 0,88 kg/dia, em animais suplementados com $0,15 \%$ do PV, no início do período de transição.

A resposta à suplementação para ganho de peso é maior quando proporciona consumo de proteína bruta maior que 0,1\%PV (Moore et al., 1999). Neste trabalho, os tratamentos com $0,125 \% \mathrm{PV}$ e $0,25 \% \mathrm{PV}$ resultaram em consumos de PB de 0,03 e $0,06 \%$ de PV, com os maiores consumos para os níveis de 0,5 e 1,0\%PV $(0,12$ e $0,24 \% \mathrm{PV}$, para a PB), durante a fase de transição.
Durante o período de seca, não houve diferença entre os ganhos de peso (0,54, 0,53, 0,60 e 0,61 kg/dia), para os níveis de fornecimento de 0,125; 0,25; 0,50 e 1,00\% de PV, respectivamente. Euclides et al. (2001), suplementando animais mantidos em pastagens com concentrado energético-protéico durante o período de seca em 0,8\%PV, encontraram ganhos de $0,49 \mathrm{~kg} / \mathrm{dia}$, porém, com disponibilidade de pastagem inferior, de $2.535 \mathrm{~kg}$ MS/ha.

Mancio et al. (1986) destacam que a suplementação protéica durante o período seco só é eficiente quando a forragem não é limitante. Durante todos os períodos os animais foram submetidos a disponibilidades superiores aos valores limitantes (Tabela 5).

Não houve diferença entre os altos níveis de fornecimento (0,5 e 1,0\% PV), com nível ótimo de 0,75\%PV (Figura 1). De acordo com Lana (2000), os animais que receberam $1,0 \%$ de PV apresentaram excesso de 2,86 kg de proteína, limitando, assim, o ganho desses animais em 0,72 kg/animal/dia. Detmann et al. (2004), pesquisando a resposta de bovinos rece- 
bendo diferentes níveis de PB no suplemento, ressaltaram que os teores de 19 a 20\%PB permitem otimizar o desempenho animal. A redução no desempenho animal com 24\%PB foi, em parte, justificada pelo excesso de proteína para o metabolismo animal, a qual pode ser perdida pela via urinária na forma de uréia, em que o gasto de síntese para uma molécula de uréia apresenta um balanço negativo de 1 ATP, o que acarreta perda de energia, prejudicando o desempenho animal.

Del Curto et al. (1990a,b) sugeriram concentração de 26\%PB no suplemento com farelo de soja e sorgo para maximizar o consumo e, posteriormente, o desempenho de bovinos de corte. Avaliando os teores de 15, 20 e 25\% de PB, Sunvold et al. (1991) sugeriram 20\% PB como a melhor concentração para maximizar o consumo de forragens, de modo que o nível de 25\% apresentou efeitos negativos. Del Curto et al. (1990a,b) e Sunvold et al.(1991) ressaltam o fraco desempenho para os baixos teores de PB, com redução de consumo e de digestibilidade, em função dos altos teores de amido contidos na dieta (>35\%).

À medida que se aumenta o fornecimento de grãos, o desempenho pode ser comprometido pelo efeito associativo entre o suplemento e a forragem, decorrente da elevação da taxa de substituição (Dixon \& Stockdale, 1999). O desempenho está diretamente relacionado ao consumo de alimentos e as variações sobre este consumo afetam diretamente o ganho de peso (Lana \& Gomes Jr., 2002).

Os ganhos de peso por unidade de área apresentaram o mesmo comportamento que o ganho de peso médio diário (Tabela 7). Os animais mantiveram um ganho constante entre os períodos com os menores valores de suplementação mineral.

As suplementações de 0,5 e 1,0\%PV proporcionaram ganhos médios de $150 \mathrm{~kg} / \mathrm{ha}$. Se compararmos com a suplementação mineral, isso demonstra uma alternativa de manejo para se alterar a produtividade,

Tabela 7 - Ganho de peso vivo por unidade de área $(\mathrm{kg} / \mathrm{ha})$, durante os períodos de transição e de seca, de animais suplementados em diferentes níveis, em função do peso vivo dos animais

Table 7 - Body weight gain by area $(\mathrm{kg} / \mathrm{ha})$ during the dry to rainy transition season and dry season of animals supplemented at different levels, according to body weight

\begin{tabular}{|c|c|c|c|c|c|c|}
\hline & \multicolumn{5}{|c|}{$\begin{array}{c}\text { Fornecimento do suplemento (\% PV) } \\
\text { Supplement level }(\% B W)\end{array}$} & \multirow[t]{2}{*}{ CV $(\%)$} \\
\hline & $\begin{array}{l}\mathrm{SM} \\
M M\end{array}$ & 0,125 & 0,25 & 0,50 & 1,00 & \\
\hline $\begin{array}{l}\mathrm{kg} / \mathrm{ha} \text { inicial } \\
\mathrm{kg} / \mathrm{ha} \text { initial }\end{array}$ & 482,8 & 520,7 & 485,9 & 533,8 & 491,5 & 10,6 \\
\hline $\begin{array}{l}\mathrm{kg} / \mathrm{ha} \text { final do período de } \\
\text { transição e início do período } \\
\text { de seca } \\
\mathrm{kg} / \mathrm{ha} \text { in the final of transition } \\
\text { and beginning of dry period }\end{array}$ & 524,3 & 604,3 & 606,9 & 683,5 & 646,0 & 12,2 \\
\hline $\begin{array}{l}\mathrm{kg} / \mathrm{ha} \text { final } \\
\mathrm{kg} / \mathrm{ha} \text { final }\end{array}$ & 597,9 & 724,3 & 724,4 & 827,7 & 795,8 & 13,2 \\
\hline $\begin{array}{l}\text { Lotação inicial (UA/ha) } \\
\text { Initial stocking rate }\end{array}$ & 1,07 & 1,14 & 1,08 & 1,19 & 1,09 & \\
\hline $\begin{array}{l}\text { Lotação final (UA/ha) } \\
\text { Final stocking rate } \\
\text { Ganho médio } \\
\text { por hectare }(\mathrm{kg} / \mathrm{ha}) \\
\text { Mean gain per hectare }(\mathrm{kg} / \mathrm{ha})\end{array}$ & 1,33 & 1,59 & 1,61 & 1,84 & 1,77 & \\
\hline $\begin{array}{l}\text { Período de transição } \\
\text { Dry to rainy transition season }\end{array}$ & 41,5 & 83,6 & 121,9 & 149,7 & 154,5 & 24,9 \\
\hline $\begin{array}{l}\text { Período de seca } \\
\text { Dry season }\end{array}$ & 73,6 & 120,0 & 117,6 & 144,2 & 149,8 & 26,9 \\
\hline $\begin{array}{l}\text { Média ponderada } \\
\text { Weighed mean }\end{array}$ & $57,5 d$ & $101,8 \mathrm{c}$ & $119,8 b c$ & $147,0 \mathrm{ab}$ & $152,2 a$ & 16,9 \\
\hline
\end{tabular}

Médias na linha seguidas de letras diferentes diferem entre si $(P<0,05)$ pelo teste Tukey.

Means in the row followed by different letters are different $(P<0.05)$ by Tukey test. 


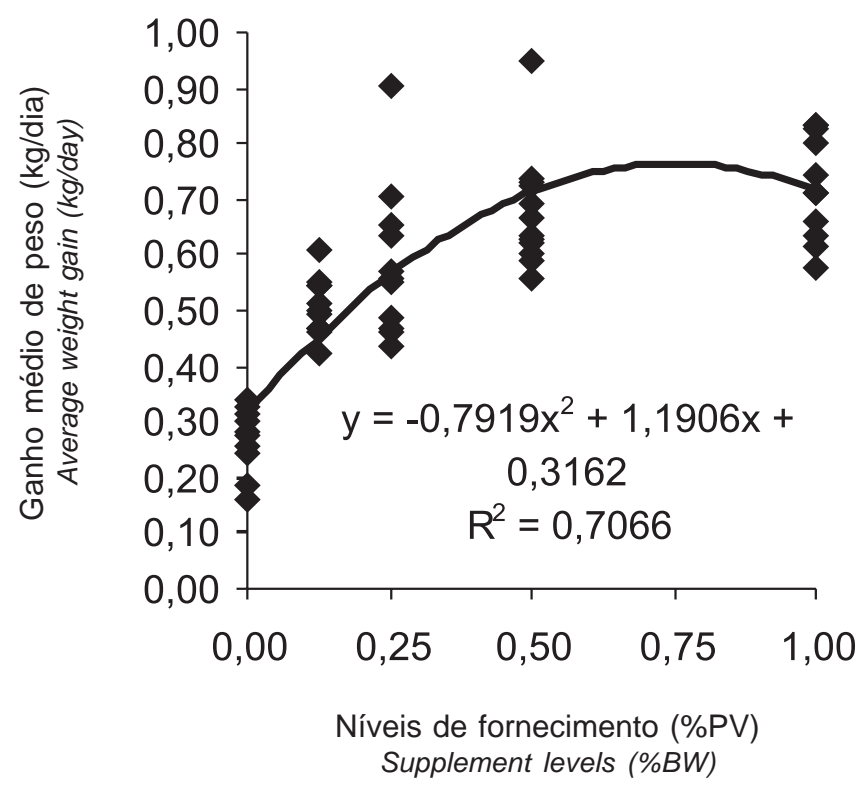

Figura 1 - Ganho de peso médio dos animais durante os períodos de transição e de seca, recebendo diferentes níveis de suplementação.

Figure 1 - Mean weight gain of animals during the transition and dry period, supplemented with different levels of supplement.

por meio do aumento da taxa de lotação. Foi observado entre os níveis mais altos de suplementação um aumento da taxa de lotação sem alterar a disponibilidade de pastagem (Tabela 5 e 7).

Neste trabalho, observou-se a ocorrência dos efeitos aditivos e substitutivos simultaneamente, uma vez que, além do aumento do ganho de peso, houve acréscimo da capacidade suporte das pastagens (Tabela 7) de 16, 25, 27 e 32\%, para os níveis estudados. Euclides et al. (2001) verificaram aumento da capacidade suporte da pastagem de 24 e $30 \%$, ao suplementarem novilhos com 0,8 a 0,9\% de PV, durante o período seco, em pastagem de $B$. decumbens.

A suplementação proporcionou elevados ganhos de peso durante os períodos estudados, porém, o custo de produção decorrente do investimento com suplementação foi elevado. Lana (2002) considera que a suplementação com quantidade liberal de concentrado para bovinos em crescimento pode ser antieconômica se o objetivo for a venda de animais para o abate. Se convertermos o ganho para peso de carcaça comercializável ((Ganho de peso - ganho de peso do tratamento testemunha) $* 0,54 * 1 / 15 * 51$ ), em que 0,54 seria o rendimento de carcaça, $1 / 15$, a conversão de kg em arroba, e 51, o custo por arroba da carcaça comercializável (região de Sinop/MT FNP 2003) e o ganho de peso $(\mathrm{kg} / \mathrm{d})$ referentes aos níveis de fornecimento e controle (Tabela 5). O retorno com relação somente ao custo de suplementação seria de $0,44,0,57,0,75$ e R\$1,24 por animal/dia, para os níveis de fornecimento de 0,125 ; 0,25; 0,50 e 1,0\%PV, respectivamente; com um custo de $0,15,0,29,0,62$, e $\mathrm{R} \$ 1,22$ por animal/dia, para os níveis de 0,125; 0,25; 0,50 e 1,0\%PV, respectivamente. A suplementação mineral apresentou custo de R \$ 0,05 por animal/dia.

Os ganhos de peso dos animais suplementados foram significativos. Esses ganhos, transformados em eficiências (kg de suplemento/kg de ganho), apresentaram valores de 1,$48 ; 1,56 ; 2,67$ e 4,43, durante o período de transição, e 1,52; 3,17; 5,29 e 10,19, durante o período de seca, para os níveis de 0,125 ; 0,25; 0,50; e 1,0\%PV, respectivamente (Tabela 8).

A conversão de ganho para os suplementos foi calculada em função do consumo de suplemento apresentado pelos animais dividido pelo diferencial de ganho de peso em relação à suplementação mineral (Tabela 6). Para o tratamento de $0,125 \%$, o diferencial para o período de transição foi de $0,21 \mathrm{~kg} / \mathrm{dia}(0,47-0,26$ $\mathrm{kg} / \mathrm{dia})$, e o consumo de suplemento de $0,31 \mathrm{~kg} / \mathrm{dia}$. A conversão de ganho em relação ao nível de fornecimento anterior foi calculada em função do ganho de peso dos animais (Tabela 5), por meio da divisão do diferencial de consumo entre os níveis de fornecimento e o diferencial de ganho de peso entre os mesmos níveis. Para os níveis de fornecimento de 0,25 e 0,5\%PV, o diferencial de consumo de suplemento foi de $0,7 \mathrm{~kg} /$ dia (1,31-0,61 kg/d) e o acréscimo de ganho durante o período de transição entre os níveis, de $0,10 \mathrm{~kg} / \mathrm{d}(0,75$ 0,65 kg; Tabela 6). Então, a conversão de ganho foi de $7: 1(0,7 / 0,1)$.

Apesar de o suplemento afetar positivamente o ganho de peso dos animais durante o período de seca, somente responderam com 0,10 quilo de ganho/ animal/dia para cada quilo de suplemento fornecido a 1,0\% PV. Lana (2000) e Lana \& Gomes Jr. (2002), analisando dados de 25 publicações entre os anos de 1989 e 1995, encontraram conversões de 14,2 e de 10,1.

Os níveis de suplementação se mostraram ineficientes quando comparados ao nível anterior. À medida que se eleva a quantidade de suplemento fornecido, o ganho de peso é reduzido (Figura 2A). O nível mais baixo apresentou melhores resultados, com uma conversão de 1,5:1, e quando se alterou o nível de 
Tabela 8 - Consumo de suplemento e eficiência do seu uso, durante os períodos de transição e de seca, para os diferentes tratamentos

Table 8 - Supplement intake and efficiency of use, during the dry to rainy transition season and dry season, according to different treatments

Fornecimento do suplemento (\% PV) Supplement level $(\% B W)$

$0,125 \quad 0,25 \quad 0,50 \quad 1,00$

Consumo de

suplemento ( $\mathrm{kg} / \mathrm{dia})$

Supplement intake ( $\mathrm{kg} /$ day)

Período de transição $0,31 \quad 0,61 \quad 1,31 \quad 2,57$

Dry to rainy transition season

Período de seca $\quad 0,38 \quad 0,76 \quad 1,64 \quad 3,26$

Dry season

Conversão de uso de

suplemento em relação

ao tratamento controle ${ }^{1}$

Supplement conversion in

relation to the control treatment ${ }^{1}$

Período de transição $\quad 1,48 \quad 1,56 \quad 2,67 \quad 4,43$

Dry to rainy transition season

$\begin{array}{lllll}\text { Período de seca } & 1,52 & 3,17 & 5,29 & 10,19\end{array}$

Dry season

Conversão de uso de

suplemento em relação

ao tratamento anterior ${ }^{2}$

Supplement conversion in

relation to the previous treatment ${ }^{2}$

$\begin{array}{lllll}\text { Período de transição } & 1,48 & 1,67 & 7,00 & 14,00\end{array}$

Dry to rainy transition season

Período de seca

$1,52-38,00 \quad 12,57162,00$

Dry season

${ }^{1}$ Conversão de ganho calculada como quilogramas de suplemento fornecido diariamente dividido pelo ganho acima daquele da suplementação mineral.

${ }^{2}$ Conversão de ganho calculada como diferencial em quilogramas de suplemento fornecido diariamente dividido pelo diferencial de ganho de peso, ambos em relação ao tratamento com menor nível de suplementação.

${ }^{1}$ Conversion of gain calculated as kilograms of supplement daily fed divided by the gain above that from mineral supplementation.

${ }^{2}$ Conversion of gain calculated as differential in kilograms of supplement daily fed divided by the differential of weight gain, both in relation to the previous treatment.

fornecimento de $0,5 \%$ PV para $1,0 \% \mathrm{PV}$, a conversão passou a ser de 36:1.

Analisando-se os dados referentes à conversão de ganho e adotando-se o modelo proposto por Lana \& Russell (1996), encontrou-se a equação $Y=0,2639 x+$ 1,3268, $\mathrm{r}^{2}=0,97$ (Figura 2B), que permitiu calcular a resposta máxima para ganho de peso $\left(\mathrm{GDP}_{\mathrm{Max}}\right)$ de $0,75 \mathrm{~kg} / \mathrm{animal} / \mathrm{dia}\left(\mathrm{GDP}_{\mathrm{Max}}=1 / \mathrm{a}=1 / 1,33\right)$, superior ao ganho apresentado pelos animais (Figura 1). A quantidade de suplemento necessária para se obter metade da

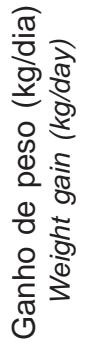

A

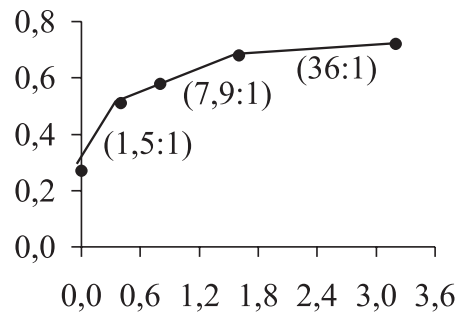

Comsumo de suplemento $(\mathrm{kg} / \mathrm{dia})$ Supplement intake ( $\mathrm{kg} / \mathrm{day})$

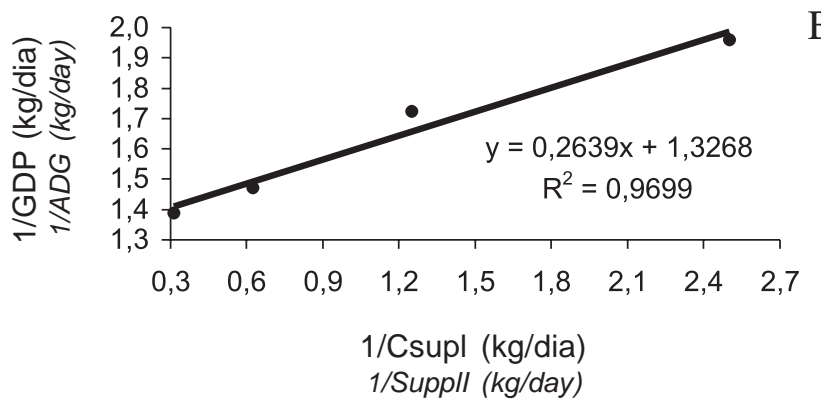

Figura 2 - Ganho de peso médio dos animais, em função do consumo de suplemento e da conversão do suplemento, em relação ao tratamento anterior ( $\mathrm{kg}$ de suplemento/kg de ganho).

Figure 2 - Mean weight gain of animals, according to supplement intake and supplement conversion in relation to the previous treatment ( $\mathrm{kg}$ of supplement/kg of gain).

resposta máxima no ganho de peso (SUPL ${ }_{50 \% G D P m a x}$ ) $=\mathrm{b} / \mathrm{a}=0,26 / 1,33=0,20 \mathrm{~kg}$ de suplemento foi de 0,125\%PV, o que, em parte, pode justificar a melhor eficiência para os animais que recebiam $0,35 \mathrm{~kg} / \mathrm{d}$.

Conversão inferior a 3:1 seria sintoma de deficiência de nitrogênio (McCollum \& Horn, 1990). Com isso, a maior resposta poderia ser atribuída ao fornecimento de energia pelo suplemento, causando efeito positivo similar aos resultados obtidos para os níveis mais baixos de suplementação. Esses resultados corroboram os de Lana $(2000,2002)$ de que o potencial de ganho dos animais foi limitado pela proteína.

Conversão igual ou maior que 8:1 seria típica de uma suplementação energética, com sintomas de substituição ou ineficiência de utilização dos nutrientes presentes no suplemento, proporcionando efeito associativo negativo (Bodine \& Purvis, 2003).

A suplementação causou uma resposta alta em ganho de peso, para uma suplementação protéica, e baixa, para uma suplementação energética, indicando 
que o nitrogênio não foi deficiente em relação à suplementação energética $(0,5$ e 1,0\%PV). As respostas apresentadas em ganho e em conversão indicam que os animais foram expostos a situações com deficiência de proteína e de energia e que esta resposta foi maior quando ambas as deficiências foram supridas pelo suplemento (Bodine \& Purvis, 2003).

\section{Conclusões}

A suplementação em níveis crescentes proporcionou maiores ganhos de peso, com nível ótimo de $0,75 \% \mathrm{PV}$ e maior conversão de ganho (kg de ganho/kg de suplemento) para os níveis de 0,125 e $0,25 \%$.

Os níveis de fornecimento acima de 0,25\% PV foram ineficientes para ganho de peso.

\section{Agradecimento}

Ao Sr. Pedro Silvestre Silva e ao Sr. Mário Wolf Filho, que forneceu os animais e os componentes da ração, tornando possível a realização deste trabalho.

\section{Literatura Citada}

BODINE, T.N.; PURVIS, H.T. Effects of supplemental energy and/or degradable intake protein on performance, grazing behavior, intake, digestibility, and fecal and blood indices by beef steers grazed on dormant native tallgrass prairie. Journal of Animal Science, v.81, p.304-317, 2003

CATON, J.S.; DHUYVETTER, D.V. Influence of energy supplementation on grazing ruminants: requirements and responses. Journal of Animal Science, v.75, p.533-542, 1997.

DE VRIES, M.F.W. Estimating forage intake and quality in grazing cattle: a reconsideration of the hand-plucking method. Journal of Range Management, v.48, n.4, p.370-375, 1995.

DEL CURTO, T.; COCHRAM, R.C.; CORAH, A.A. et al. Supplementation or dormant tallgrass-praire forage. II. Performance and forage utilization characteristics in grazing beef cattle receiving supplements of different protein concentrations. Journal of Animal Science, v.68, p.532542, 1990a.

DEL CURTO, T.; COCHRAM, R.C.; HARMON, D.L. et al. Supplementation of dormant, tallgrass-praire forage: I. Influence of varying supplemental protein and(or) energy levels on forage utilization characteristics of beef steers in confinament. Journal of Animal Science, v.68, p.515531, 1990b.

DETMANN, E.; PAULINO, M.P.; ZERVOUDAKIS, J.T. et al. Níveis de proteína bruta em suplementos múltiplos para terminação de novilhos mestiços em pastejo durante a época seca: desempenho produtivo e características de carcaça. Revista Brasileira de Zootecnia, v.33, n.1, p.169-180, 2004.
DIXON, R.M.; STOCKDALE, C.R. Associative effects between forages and grains: consequences for feed utilization. Australian Journal of Agricultural Research, v.50, n.5, p.757-774, 1999.

EUCLIDES, V.P.B.; EUCLIDES FILHO, K.; ARRUDA, Z.J. et al. Desempenho de novilhos em pastagem de Brachiaria decumbens submetidos a diferentes regimes alimentares. Revista Brasileira de Zootecnia, v.27, n.2, p.246-254, 1998. EUCLIDES, V.P.B.; EUCLIDES FILHO, K.; COSTA, F.P.; et al. Desempenho de novilhos F1s Angus-Nelore em pastagens de Brachiaria decumbens submetidos a diferentes regimes alimentares. Revista Brasileira de Zootecnia, v.30, n.2, p.470-481, 2001.

EUCLIDES, V.P.B.; MACEDO, M.C.M.; OLIVEIRA, M.P. Avaliação de diferentes métodos de amostragem (para se estimar o valor nutritivo de forragens) sob pastejo. Revista Brasileira de Zootecnia, v.21, n.4, p.691-702, 1992.

FNP - Consultoria \& Comércio - Abate de bovinos no Brasil. Acessado em Dezembro de 2003. www.fnp.com.br/pecuaria/ boigordo/prod cab.php

GARCES-YEPEZ, P.; KUNKLE, W.E.; BATES, D.B. et al. Effects of supplemental energy source and amount on forage intake and performance by steers and intake and digestibility by sheep. Journal of Animal Science, v.75, p.1918-1925, 1997.

GOES, R.H.T.B; MANCIO, A.B.; LANA, R.P. et al. Avaliação qualitativa da pastagem de capim tanner grass (Brachiaria arrecta), por três diferentes métodos de amostragem. Revista Brasileira de Zootecnia, v.32, n.1, p.64-69, 2003a.

GOES, R.H.T.B.; MANCIO, A.B.; LANA, R.P. et al. Desempenho de novilhos Nelore em pastejo na época das águas: ganho de peso, consumo e parâmetros ruminais. Revista Brasileira de Zootecnia, v.32, n.1, p.214-221, 2003b.

HORN, G.W.; McCOLLUN, F.T. Energy supplementation of grazing ruminants. In: GRAZING LIVESTOCK NUTRITION CONFERENCE, 1987, Jackson. Proceedings... Jackson: 1987. p.125-136.

JOHNSON, A.D. Sample preparation and chemical analysis of vegetation. In: MANETJE, L.T. (Ed.) Measurament of grassland vegetation and animal production. Aberustwyth: Commonwealth Agricultural Bureaux, 1978. p.96-102.

KABEYA, K.S.; PAULINO, M.P.; DETMANN, E. et al. Suplementação de novilhos mestiços em pastejo na época de transição água-seca: Desempenho produtivo, características físicas de carcaça, consumo e parâmetros ruminais. Revista Brasileira de Zootecnia, v.31, n.1, p.213-222, 2002.

KUNKLE, W.E.; JOHNS, J.T.; POORE, M.H.; et al. Designing supplementation programs for beef cattle fed forage-based diets. Proceedings of the American Society of Animal Science, 2000. Disponível em www.asas.org/jas/symposia/ proceedings/0912.pdf

LANA, R.P.; GOMES JR., P. Sistema de suplementação alimentar para bovinos de corte em pastejo. Validação. Revista Brasileira de Zootecnia, v.31, n.1, p.451-459, 2002 (suplemento).

LANA, R.P.; RUSSELL, J.B. Use of potassium depletion to assess adaptation of ruminal bacteria to ionophores. Applied and Environmental Microbiology, v.62, n.12, p.4499-4503, 1996.

LANA, R.P. Sistema de suplementação alimentar para bovinos de corte em pastejo. Simulação. Revista Brasileira de Zootecnia, v.31, n.1, p.223-231, 2002. 
LANA, R.P. Sistema Viçosa de formulação de rações. Viçosa, MG: Universidade Federal de Viçosa, 2000. 60p.

MANCIO, A.B.; VIANA, J.A.C.; AZEREDO, N.A. et al. Efeito da suplementação com semente de soja e uréia no período de seca sobre o potencial reprodutivo de fêmeas zebu. Arquivos da Escola de Veterinária, v.26, n.6, p.1243-1251, 1986.

MANELLA, M.Q.; LOURENÇO, A.J.; LEME, P.R. Recria de bovinos Nelore em pastos de Brachiaria brizantha com suplementação protéica ou com acesso a banco de Leucaena leucephala. Desempenho animal. Revista Brasileira de Zootecnia, v.31, n.6, p.2274-2282, 2002.

McCOLLUN, F.T.; HORN, G.W. Protein supplementation of grazing livestock: A review. Professional Animal Scientist, v.6, p.1-16, 1990.

MINSON, D.J. Forage in ruminant nutrition. New York: Academic Press, 1990. 483p.

MOORE, J.E.; BRANT, M.H.; KUNKLE, W.E.; et al. Effects of supplementation on voluntary forage intake, diet digestibility, and animal performance. Journal of Animal Science, v.77, suppl. 2, p.122-135, 1999.

MORAIS, M.G., BORGES, A.L.C.C., GONÇALVES, L.C. et al. Variação da parede celular da Brachiaria decumbens Fibra em detergente neutro, fibra em detergente ácido, celulose e lignina. In: REUNIÃO ANUAL DA SOCIEDADE BRASILEIRA DE ZOOTECNIA, 33., 1998, Botucatu. Anais... São Paulo: SBZ/Gnosis, [1998]. CD-ROM. Forragicultura FOR-252.

PAULINO, M.F. Misturas múltiplas na nutrição de bovinos de corte a pasto. In: SIMPÓSIO GOIANO SOBRE PRODUÇÃO DE BOVINOS DE CORTE, 1999, Goiânia. Anais... Goiânia: Colégio Brasileiro de Nutrição Animal, 1999. p.95-105.

PAULINO, M.F. Suplementação de bovinos em pastejo. Informe Agropecuário, v.21, n.205, p.96-106, 2000.

PAULINO, M.F.; DETMANN, E.; ZERVOUDAKIS, J.T. Suplementos múltiplos para recria e engorda de bovinos em pastejo. In: SIMPÓSIO DE PRODUÇÃO DE GADO DE CORTE, 2., 2001, Viçosa, MG. Anais... Viçosa, MG: Universidade Federal de Viçosa, 2001. p.187-231.

PERUCHENA, C.A. Suplementácion de bovinos para carne sobre pasturas tropicales, aspectos nutricionales, productivos y economicos. In: REUNIÃO ANUAL DA SOCIEDADE BRASILEIRA DE ZOOTECNIA, 36., 1999, Porto Alegre. Anais... Porto Alegre: Sociedade Brasileira de Zootecnia, p.199-212.
PRADO; I.N.; MOREIRA, F.B.; CECCATO, V. et al. Sistemas para crescimento e terminação de bovinos de corte a pasto: avaliação do desempenho animal e caracteristicas de forragem. Revista Brasileira de Zootecnia, v.32, n.4, p.955-965, 2003.

SANTOS, E.D.G.; PAULINO, M.P.; QUEIROZ, D.S. et al. Avaliação de pastagem diferida de Brachiaria decumbens Stapf. 2. Disponibilidade de forragem e desempenho animal durante a seca. Revista Brasileira de Zootecnia, v.33, n.1, p. 214-224, 2004.

SILVA, D.J.; QUEIROZ, A.C. Análise de alimentos: métodos químicos e biológicos. Viçosa, MG: Universidade Federal de Viçosa, 2002. 239p.

SUNVOLD, G.D.; COCHRAM, R.C; VANZANT, E.S. Evaluation of wheat middling as a supplement for beef cattle consuming dormant bluestem-range forage. Journal of Animal Science, v.69, p.3044-3054, 1991.

THIAGO, L.R.L.S. Suplementação de bovinos a pasto (aspectos práticos para o seu uso na mantença ou ganho de peso). Embrapa Gado de Corte - CNPGC. Campo Grande - MS Disponível em www.cnpgc.embrapa.br/publicações/ naoseriadas/suplementhiago, acessado em 03/2000.

TILLEY, J.M.A.; TERRY, R.A. A two-stage technique for the in vitro digestion of forage crops. Journal of Brithsh Grassland Society, v.18, p.104-111, 1963.

UNIVERSIDADE FEDERAL DE VIÇOSA - UFV. SAEG Sistema de análises estatísticas e genéticas. Versão 8.0. Viçosa, MG. (manual do usuário), 2000. 142p.

ZERVOUDAKIS, J.T. Suplementos múltiplos de autocontrole de consumo e freqüências de suplementação, na recria de novilhos durante o período das águas e de transição águas-seca. Viçosa, MG: Universidade Federal de Viçosa, 2003, 76p. Tese (Doutorado em Zootecnia) - Universidade Federal de Viçosa, 2003.

ZERVOUDAKIS, J.T.; PAULINO, M.P.; DETMANN, E.; et al. Desempenho e características de carcaça de novilhos suplementados no período das águas. Revista Brasileira de Zootecnia, v.30, n.4, p.1381-1389, 2001.

Recebido em: 01/07/04 Aceito em: 18/04/05 